\title{
INTENÇÃO EMPREENDEDORA ENTRE ESTUDANTES UNIVERSITÁRIOS: INFLUÊNCIA DAS CARACTERÍSTICAS E TREINAMENTO EMPREENDEDOR
}

\section{ENTREPRENEURIAL INTENT AMONG UNIVERSITY STUDENTS: INFLUENCE OF CHARACTERISTICS AND ENTREPRENEURIAL TRAINING}

\author{
PAULA REGINA ZARELLI \\ Universidade Tecnológica Federal do Paraná - UTFPR \\ Professora da Universidade Tecnológica Federal do Paraná (UTFPR) \\ Administradora, Doutora em Engenharia e Gestão do Conhecimento pela Universidade Federal de \\ Santa Catarina - UFSC \\ Orcid: http://orcid.org/0000-0002-0279-6933 / E-mail: przarelli@utfpr.edu.br \\ Rua Cézar Augusto Frasson, 107, Apartamento 21, Jardim Tocantins, Toledo - PR, 85.903-343
}

EVELLIN MEDEIROS OTTO

Universidade Tecnológica Federal do Paraná - UTFPR

Acadêmica em Engenharia de Bioprocessos e Biotecnologia

Orcid: http://orcid.org/0000-0002-0047-2003 / E-mail: eve.otto@hotmail.com

\author{
SILVESTRE LABIAK JUNIOR \\ Universidade Tecnológica Federal do Paraná - UTFPR \\ Professor da Universidade Tecnológica Federal do Paraná (UTFPR) \\ Pós-doutor em Engenharia e Gestão do Conhecimento pela Universidade Federal de Santa Catarina - \\ UFSC \\ Orcid: http://orcid.org/0000-0001-5336-6223 / E-mail: slabiakjr@gmail.com
}

Submissão: 10/07/2020. Revisão: 22/01/2021. Publicação: 21/10/2021.

DOI: http://dx.doi.org/10.22277/rgo.v14i3.5249

\section{RESUMO}

O objetivo foi analisar a influência das características empreendedoras e treinamento empreendedor na intenção empreendedora de estudantes universitários. A pesquisa foi descritiva, com abordagem quantitativa, procedimentos estatísticos e delineamento transversal, com amostra composta por 403 estudantes universitários de todos os cursos de graduação da Universidade Tecnológica Federal do Paraná - Campus Francisco Beltrão - PR. A análise de regressão multivariada permitiu analisar a influência proposta no modelo confirmatório, explicando $47,3 \%$ e $25,6 \%$ da sua variância. Estes resultados se relacionam com o interesse crescente na formação para o empreendedorismo, expresso por políticas, instituições de ensino superior e estudantes. Contribuições sociais são expressas nas variáveis socioambientais presentes na característica empreendedora e na intenção de empreender. A originalidade do estudo consiste na aplicação do modelo internacional adaptado de Küttim et al. (2014) e Adekiya e Ibrahim (2016) no contexto brasileiro. Demonstrou-se que a característica empreendedora contribui para o desenvolvimento das intenções empreendedoras dos alunos. Verificou-se que a participação na formação em âmbito de treinamento para o empreendedor exerce um impacto positivo nas intenções empreendedoras.

Este é um artigo publicado em acesso aberto (Open Access) sob a licença Creative Commons Attribution, que permite uso, distribuição e reprodução em qualquer meio, sem restrições desde que o trabalho original seja corretamente citado. 
Palavras-chave: Característica empreendedora. Intenção empreendedora. Estudantes universitários. Treinamento empreendedor. Empreendedorismo social.

\begin{abstract}
The aim to analyze the influence of entrepreneurial characteristics and entrepreneurial training on the entrepreneurial intention of university students. The research was descriptive, with quantitative approach, statistical procedures and cross - sectional design, with a sample composed of 403 university students from all courses of the Federal Technological University of Paraná - Francisco Beltrão - Paraná/Brazil. Multivariate regression analysis allowed us to analyze the proposed influence on the confirmatory model, explaining $47.3 \%$ and $25.6 \%$ of its variance. These results relate to the growing interest in entrepreneurship education, expressed by policies, higher education institutions and students. Social contributions are expressed in the social and environmental variables present in the entrepreneurial characteristic and the intention to undertake. The originality of the study is the application of the international model adapted from Küttim et al. (2014) and Adekiya and Ibrahim (2016) in the Brazilian context. The entrepreneurial characteristic has been shown to contribute to the development of the entrepreneurial intentions of the students. Participation in entrepreneurial training has a positive impact on entrepreneurial intentions.
\end{abstract}

Keywords: Entrepreneurial characteristic. Entrepreneurial intention. University students. Entrepreneurial training. Social entrepreneurship.

\title{
1 INTRODUÇÃO
}

O crescente interesse pelo empreendedorismo se justifica pela relevância que as pequenas e microempresas têm na economia (JÚNIOR; GIMENEZ, 2004). De acordo com dados do relatório GEM (2017), no Brasil, o número de pessoas que opta pelo empreendedorismo como meio de vida aumenta anualmente (PIRES; PICCHIAI; AYRES, 2021).

As definições para empreendedorismo são várias, mas sua essência se resume em fazer diferente, empregar os recursos disponíveis de forma criativa, assumir riscos calculados, buscar oportunidades e inovar (DORNELAS, 2004). Uma das vertentes da atual literatura sobre empreendedorismo vislumbra o empreendedor como um criador de redes. Destoando da concepção dominante do empreendedor como um ator atomizado e individualista, traz interessantes desdobramentos, tanto no plano teórico quanto da observação empírica. Os empreendedores não apenas definem situações, mas também imaginam visões sobre o que desejam alcançar. Sua tarefa principal parece ser a de imaginar e definir o que querem fazer e, quase sempre, como irão fazê-lo (FILION, 2000). No entanto, o tema empreendedorismo pode apresentar limitações, no sentido de representar desafios, devido ao processo de transformação vertiginoso pelo qual o mundo está passando, em que a inovação representa a mola mestra. (VALE; WILKINSON; AMÂNCIO, 2008).

O que os empreendedores fazem está intimamente ligado à maneira como interpretam o que está ocorrendo em um setor em particular do meio. Seu conhecimento de um mercado específico ou do desenvolvimento de um novo produto ou de um novo processo fabril irá levá-los a ter uma visão de alguma coisa diferente e a comercializá-la. 
Intenção empreendedora entre estudantes universitários:

influência das características e treinamento empreendedor

Definem maneiras de fazer as coisas que refletem o que eles próprios são, e o sucesso deles depende do quanto aquilo foi definido, é adequado e diferente e o quanto isso satisfaz as necessidades variáveis das pessoas (FILION, 2000).

O empreendedor é, por excelência, o agente detentor dos "mecanismos de mudança", com capacidade de explorar novas oportunidades, pela combinação de distintos recursos ou diferentes combinações de um mesmo recurso. As inovações podem contrabalançar ou compensar a tendência a taxas de retorno decrescentes na indústria ou na economia em geral. A habilidade de identificar e perseguir novas formas de associação de recursos e novas oportunidades no mercado é a atividade empreendedora por excelência (VALE; WILKINSON; AMÂNCIO, 2008).

Assim, a necessidade de desenvolver um espírito crítico e de análise, para a condução de um auto sustento se faz, cada vez mais, um diferencial, em um cenário onde as novas tecnologias de produção e de informação são a busca para melhores resultados nas empresas (SOUZA et al., 2004). Em Miguez e Lezana (2018), o empreendedorismo corporativo é definido como a criação de nova riqueza em uma empresa a partir de novas combinações de recursos.

Diante do exposto, verificam-se duas questões principais relativas ao empreendedor, a primeira voltada para a criação de empresas, e a segunda, relativa a existência de aspectos concernentes à inovação e a tecnologia (SOUZA et al., 2004).

Pondera-se, adicionalmente, a preocupação de políticas sociais, que centram-se no local, na territorialidade de medidas, na negociação de direitos e objetivos com os atores sociais, na participação destes, na criação de parcerias ativas locais e rentabilização de recursos face ao desenvolvimento social (RAMOS, 2013). Neste cenário insere-se o conceito de empreendedorismo social, cujas características se apresentam de diversas formas na literatura.

O empreendedorismo social caracteriza-se por ações coletivas com objetivo de solucionar problemas sociais, estando associado ao desenvolvimento de projetos de indivíduos ou de comunidades, não necessariamente envolvidos numa organização, e visando alcançar o interesse geral, o bem comum, ou responder a necessidades sociais não satisfeitas. O empreendedor social cria riqueza e melhora as condições de vida da população, exercendo uma atividade empresarial para benefício público ou social, e não com o intuito do lucro (RAMOS, 2013).

Em Garcia et al. (2021), tem-se que a medida de desempenho do empreendedorismo privado é o lucro por ele gerado e o desempenho do empreendedorismo social é medido pelo impacto social e pelas mudanças sociais que ele produz. Os autores enfatizam que o conceito de empreendedorismo social é comumente definido a partir da criação de valor social e seus benefícios e, consequentemente, é entendido como um importante mecanismo de mudança social.

Adicionalmente, Rivera et al. (2018) e Garcia et al. (2021) entendem que o empreendedorismo social contribui com o bem-estar da população, gera empregos e pode, também, gerar crescimento econômico.

Somado às características do empreendedor e a inclusão do tema social no perfil empreendedor, há o aspecto da formação deste profissional. Xavier (2018) enfatiza a relevância do estudo sobre atitude empreendedora em estudantes universitários, atribuindo o desenvolvimento e até mesmo a sobrevivência das organizações em grande parte através da formação e da capacitação dos seus atores. 
Alinhado a esta perspectiva, Schaefer e Minello (2016) e Pires, Picchiai e Ayres (2021) apontam que os professores são os responsáveis por estimular os discentes a pensarem e a agirem com uma mentalidade empreendedora, sendo necessário para isso apresentarem as características adequadas, como experiência profissional, práticas empreendedoras e perfil realizador e visionário.

Souza et al. (2004) ressaltam que a implementação de cursos de empreendedorismo para estudantes nas mais diversas áreas do ensino superior capacita os indivíduos a serem empreendedores, sendo a promoção do empreendedorismo uma das soluções apontadas para redução da taxa de desemprego em Portugal.

Estudos anteriores analisam o perfil empreendedor de estudantes universitários em diversos contextos, Souza et al. (2004) em Portugal; Eckert et al. (2013) no contexto da Universidade de Caxias do Sul - RS; Meneghatti et al. (2015) na Unioeste - PR; Araújo e Carvalho (2016) no Sul do Brasil; Xavier (2018) no Distrito Federal; Ferreira, Alcântara e Freitas (2013) avaliaram o potencial empreendedor em uma Instituição de Ensino Superior na Nigéria; bem como Küttim et al. (2014) em dezessete países europeus; e, Adekiya e Ibrahim (2016), na Bayero University Kano na Nigéria, propuseram a mensuração da intenção empreendedora.

Estes estudos evoluíram das afirmações de Ferreira, Alcântara e Freitas (2013), como posto por Dolabela $(1999$, p. 23) de que "ainda não existe resposta científica sobre se é possível ensinar alguém a ser empreendedor. Mas sabe-se que é possível aprender a sê-lo". A mesma ideia é vista em Filion (2000), para o qual as pessoas podem aprender a ser empreendedoras. Meneghatti et al. (2015) reiteram que a mensuração de um perfil empreendedor não é uma tarefa fácil, existindo na literatura uma diversa gama de estudos que se propuseram a identificar instrumentos e modelos para sua medição.

A pesquisa sobre empreendedorismo, por sua própria natureza, é um campo multi e interdisciplinar de investigação, além disso, o campo é explicitamente aberto e exige novas perspectivas, mais pesquisas e práticas que contribuam para a sua distinção e desenvolvimento (FRANCO; GOUVÊA, 2016).

Assim, este estudo visa analisar a influência das características e do treinamento empreendedor na intenção empreendedora de estudantes universitários da Universidade Tecnológica Federal do Paraná, campus Francisco Beltrão.

\section{CARACTERÍSTICAS E INTENÇÃO EMPREENDEDORAS}

As características empreendedoras são descritas na literatura desde 1700 por Cantillon, que referenciava o empreendedor como um tomador de decisões racional. Além de ser um tomador de decisões o empreendedor é identificado como criador e desenvolvedor de algo que não foi pensado por ninguém anteriormente (ARAÚJO; CARVALHO, 2016). Em Xavier (2018), tem-se uma perspectiva mais ampla relativa ao empreendedor, como o que possui um conjunto de práticas apropriadas para garantir a geração de riqueza e um melhor funcionamento àquelas sociedades que o apoiam e o praticam. E esclarece que o interesse está na identificação dos valores, hábitos e competências que o indivíduo empreendedor deve apresentar como características e, com maior relevância, como desenvolver essas competências no âmbito profissional.

Há três eras do pensamento empreendedor de acordo com Landström e Lohrke (2010): Era Econômica (1870-1940); Era Ciências Sociais (1940-1970); e, Era Estudos de Gestão (a partir de 1970), sendo o enfoque comportamental com ênfase nas características 
Intenção empreendedora entre estudantes universitários:

influência das características e treinamento empreendedor

do indivíduo para explicar o perfil empreendedor, influenciado principalmente por McClelland (1965) e Collins e Moore (1964), na Era Ciências Sociais.

Um quadro evolutivo das características empreendedoras expostas por Santos (2008) é adaptado por Ferreira, Alcântara e Freitas (2013).

Quadro 1 - Resumo das Características Empreendedoras

\begin{tabular}{|c|c|c|}
\hline Ano & Autor(es) & Características \\
\hline 1755 & R. Cantillon & $\begin{array}{l}\text { Tende a lidar com incertezas e toma decisões racionais, } \\
\text { assume riscos }\end{array}$ \\
\hline 1848 & J.S. Mill & Capacidade de enfrentar riscos \\
\hline 1917 & M. Weber & Fonte de autoridade formal \\
\hline 1934 & J.A. Schumpeter & Inovação, iniciativa \\
\hline 1954 & F. X. Sutton & Ânsia por responsabilidade \\
\hline 1959 & H. Hartman & Fonte de autoridade formal \\
\hline 1961 & D.C. McClelland & Assume riscos, tem necessidade de realização \\
\hline 1963 & L. E. Davids & $\begin{array}{l}\text { Ambição, desejo de ser independente, responsabilidade, } \\
\text { Autoconfiança }\end{array}$ \\
\hline 1964 & H. B. Pickle & $\begin{array}{l}\text { Direção pelo intelecto, relações humanas, habilidade de } \\
\text { comunicação, conhecimento técnico }\end{array}$ \\
\hline 1971 & M. Palmer & Mede os riscos \\
\hline 1971 & $\begin{array}{l}\text { J. A. Homaday e J. } \\
\text { Abound }\end{array}$ & $\begin{array}{l}\text { Necessidade de realização, autonomia, agressão, poder, } \\
\text { reconhecimento, inovativo/independente }\end{array}$ \\
\hline 1973 & D. G. Winter & Necessidade de poder \\
\hline 1974 & C. Borland & Locus interno de controle \\
\hline 1974 & P. R. Liles & Necessidade de realização \\
\hline 1977 & Y. Gasse & Orientado por valores pessoais \\
\hline 1978 & J. A. Timmons & $\begin{array}{l}\text { Direcionado/auto-confiante, orientado por metas, assume } \\
\text { riscos moderados; locus de controle; criatividade/inovação }\end{array}$ \\
\hline 1980 & D. L. Sexton & Energizado/ambicioso, recuos positivos \\
\hline 1981 & $\begin{array}{l}\text { J. A. Welsh e J. F. } \\
\text { White }\end{array}$ & $\begin{array}{l}\text { Necessidade de controlar, busca responsabilidades, } \\
\text { autoconfiante/direcionado, aceita desafios, assume riscos }\end{array}$ \\
\hline 1982 & $\begin{array}{l}\text { W. C. Dunkelberg } \\
\text { e A. C. Cooper }\end{array}$ & $\begin{array}{c}\text { Direcionado ao crescimento, direcionado à independência a } \\
\text { fazer as coisas com suas próprias mãos }\end{array}$ \\
\hline 1982 & $\begin{array}{l}\text { F. Hoy e D. } \\
\text { Hellriegel }\end{array}$ & $\begin{array}{l}\text { Preferências por tarefas técnicas em vez de tarefas } \\
\text { administrativas }\end{array}$ \\
\hline 1983 & $\begin{array}{l}\text { C. M. Pavett e A. } \\
\text { W. Lau }\end{array}$ & $\begin{array}{l}\text { Conceitual, humano e politicamente competente, } \\
\text { familiarizado tecnicamente em um campo especializado }\end{array}$ \\
\hline 1985 & P. F. Drucker & Inovador, criador de novos mercados e novos consumidores \\
\hline 1987 & E. H. Schein & $\begin{array}{l}\text { Fortes habilidades de gestão com altos níveis de } \\
\text { responsabilidade e autoridade, especialista versus gestor } \\
\text { geral }\end{array}$ \\
\hline 1987 & $\begin{array}{l}\text { J. A. Timmons, D. } \\
\text { F. Muzyka }\end{array}$ & $\begin{array}{l}\text { Habilidade para pressentir e reconhecer vantagens durante } \\
\text { a busca de oportunidades }\end{array}$ \\
\hline 1989 & $\begin{array}{l}\text { T. L. Wheelen e J. } \\
\text { D. Hunger }\end{array}$ & Habilidade para implementar estratégias \\
\hline 1992 & $\begin{array}{l}\text { G. N, Chandler e } \\
\text { E. Jansen }\end{array}$ & Habilidade pessoal para reconhecer oportunidade \\
\hline
\end{tabular}


Paula Regina Zarelli, Evellin Medeiros Otto e Silvestre Labiak Junior

\begin{tabular}{|c|c|c|}
\hline 1994 & $\begin{array}{c}\text { N. G. Boyd e G. S. } \\
\text { Vozikis }\end{array}$ & Auto-eficácia \\
\hline 2005 & $\begin{array}{c}\text { S. Beugelsdijk e } \\
\text { N. Noorderhaven }\end{array}$ & Mais individualmente orientado do que o resto da \\
população
\end{tabular}

Fonte: Ferreira, Alcântara e Freitas (2013).

Em Verga e Silva (2014), tem-se que o fenômeno do empreendedorismo, e por conseguinte suas características, são complexos demais para serem analisados apenas sob um ponto de vista. Na área da Administração, por exemplo, a perspectiva do empreendedor se situa em um contexto de expansão e pesquisas quanto ao papel desse agente como um futuro gestor do seu negócio.

Adekiya e Ibrahim (2016) definem empreendedor como o indivíduo que se empenha em um comportamento econômico, com a intenção de criar e agregar valor para encontrar e atender necessidades humanas.

Nos estudos sobre empreendedorismo, houve um interesse de estudar as características dos empreendedores em situações ex-post para estudar fatores que levem à decisão de fundar uma empresa para poder explicar o comportamento empreendedor (KÜTTIM et al., 2014). Os pesquisadores propuseram e elaboraram vários modelos de intenção, considerando que as intenções empreendedoras podem ser influenciadas por convicções relacionadas a variáveis pessoais.

Nesta linha, Oliveira (2006) estabelece que o desenvolvimento de intenção empreendedora depende da combinação de fatores pessoais e de fatores sociais. Estes autores referem-se aos estudos Moriano et al. (2007) e Ajzen (1987) no sentido de que a intenção empreendedora é a cognição que orienta e guia a ação do empreendedor para a criação e desenvolvimento de uma nova empresa, sendo que a intenção surge como o antecedente do comportamento e, quanto mais forte é a intenção de desenvolver um determinado comportamento, maior será a probabilidade da sua realização efetiva.

Krueger et al. (2000) são mencionados por Oliveira (2006), tendo em vista que os modelos de intenção empreendedora funcionam como modelos sólidos, generalizáveis e constituem um marco teórico robusto para analisar e predizer a intenção empreendedora a partir de uma perspectiva integradora e ecossistêmica da pessoa e do seu contexto.

Assim, este estudo considera a característica empreendedora como uma variável que pode exercer impacto ou influência na intenção empreendedora, sendo um preditor cultural (ADEKIYA; IBRAHIM, 2016) e torna possível buscar evidências empíricas para a análise na construção das hipóteses, sendo:

H1: A característica empreendedora possui algum efeito positivo e significativo na intenção de empreender.

\section{TREINAMENTO EMPREENDEDOR E A UNIVERSIDADE}

No cenário atual, as universidades buscam alternativas para desenvolverem uma formação empreendedora nas diferentes áreas do conhecimento e, por excelência, na da administração da inovação, passando a formar pessoas pró - ativas, criativas, inovadoras, ou seja, empreendedoras (SOUZA et al., 2004).

Segundo Degen (2008), o Brasil tem somente 55\% da atividade empreendedora motivada por oportunidades, enquanto os EUA têm $80 \%$, conforme mostra pesquisa do 
Intenção empreendedora entre estudantes universitários:

influência das características e treinamento empreendedor

Global Entrepreneurship Monitor (GEM). A solução, segundo o autor, seriam escolas técnicas e universidades implementarem uma reestruturação em seus currículos, colocando cursos de empreendedorismo em suas grades, o que levaria a um incentivo de empreender por oportunidade. $\mathrm{O}$ empreendedorismo por oportunidade tem um significante maior impacto sobre o crescimento econômico de um país do que o empreendedorismo por necessidade (DEGEN, 2008).

Souza et al. (2004) relatam que para dar resposta a essas demandas, busca-se novas estratégias institucionais e estruturas curriculares, além de alternativas metodológicas inovadoras, movimentos de inserção da cultura empreendedora no contexto das universidades, com o propósito de redirecionar seu processo de ensino-aprendizagem.

Logo, a importância da disseminação de uma cultura empreendedora nas instituições de ensino superior, na tentativa de propiciar um ambiente empreendedor para os futuros profissionais é fundamental (SOUZA et al., 2004). Nesta visão, os autores afirmam que se torna cada vez mais frequente a necessidade de os egressos do ensino superior criarem, por si mesmos, seus postos de trabalho, o que leva a um processo de revisão e adequação do processo ensino-aprendizagem universitário, e a importância da adoção de projetos pedagógicos desenhados com metodologias alternativas e inovadoras.

Ainda para os autores, a formação empreendedora baseia-se na imaginação, na criatividade, associadas à inovação. Dessa forma, passa a ser importante criar um ambiente favorável ao empreendedorismo, no qual estejam incluídos espaços de discussão e reflexão e um sistema de suporte que incentive o jovem empreendedor.

Dal Soto, Souza e Benner (2020) utilizam a lógica de Philpott et al. (2011) para classificar as atividades acadêmicas voltadas ao empreendedorismo, como soft e hard. 0 contínuo entre soft e hard está relacionado à sofisticação empreendedora em cada atividade acadêmica, considerando a publicação, captação de recursos e consultoria como atividades mais brandas (soft), e parque tecnológico, empresa spin-off e patenteamento como atividades mais duras (hard).

Alguns desses fatores que influenciam na atividade empreendedora em um país são a educação e o treinamento da população, o número e a qualidade dos centros de pesquisa e de tecnologia, a disponibilidade de capital de risco, a profundidade do mercado, a existência de uma infraestrutura adequada e uma legislação que facilite a atividade empreendedora (DEGEN, 2008).

$\mathrm{Na}$ visão de Lima et al. (2014), os estudantes podem se beneficiar com o desenvolvimento de conhecimentos e habilidades do empreendedorismo com a Educação em Empreendedorismo, mesmo que não queiram ter seu próprio negócio.

Em um nível mais amplo, Küttim et al. (2014) esclarece que a educação para o empreendedorismo pode ser colocada em um contexto mais amplo do que as empresas que preparam não apenas uma pessoa que pode se tornar autônoma e proprietária de uma empresa, mas também uma pessoa capaz de buscar empreendedorismo e inovação como funcionário e / ou pessoa que exibe comportamento empreendedor.

Segundo estudo feito por Souza et al. (2004), das 131 Instituições de Ensino Superior - IES, das 16 unidades federativas brasileiras, que fizeram parte da pesquisa empreendedora, aproximadamente 86 (66\%) estão trabalhando com empreendedorismo, sendo a maior parte, 54\%, em IES públicas. A partir das informações das entrevistas realizadas, participaram das atividades de empreendedorismo, de 1998 a 2002, 74.060 alunos, dos quais $42 \%$ nas IES públicas e $58 \%$ nas privadas. Cerca de 69\%, isto é, 90 das 131 IES pesquisadas, desenvolvem atividades de ensino nesta área. 
No contexto internacional, e contra o pano de fundo do desemprego, o governo federal da Nigéria instruiu que Instituições de ensino superior do país estabelecessem centros de estudo do empreendedorismo, onde cursos sobre o tema devem ser ensinados, a fim de equipar os formandos com as competências necessárias que podem melhorar o seu auto emprego após a graduação, em vez de procurar empregos que não estão prontamente disponíveis (ADEKIYA; IBRAHIM, 2016).

No cenário brasileiro, a Universidade Tecnológica Federal do Paraná, por meio da Agência de Inovação da instituição, operacionaliza e estimula o Programa de Empreendedorismo e Inovação - Proem. O Proem é um dos mecanismos de apoio às ações de empreendedorismo e inovação desenvolvidas na UTFPR. Tem como objetivo possibilitar aos alunos, ex-alunos, servidores e comunidade regional externa, o acesso à cultura do empreendedorismo e da inovação. Atua na formação da cultura empresarial e propicia espaços de desenvolvimento para projetos e empresas base tecnológica por meio do Hotel Tecnológico, Incubadora de Inovações Tecnológicas e Empresas Júniores (http://portal.utfpr.edu.br/inovacao/agencia).

Desta forma, a instituição promove o treinamento empreendedor por meio de diversas iniciativas, sendo que os treze campi no Paraná realizam, dentre várias ações, o Programa Escalada, voltado para as ideias inovadoras em fase de desenvolvimento (Hotel Tecnológico) ou em fase de aplicação (Incubadora de Inovações).

O treinamento empreendedor diz respeito ao microambiente institucional, como oferta de cursos, tipos de conhecimento empreendedor como legislação, por exemplo, e reação ao treinamento como desenvolvimento de habilidade empreendedora e satisfação em participar.

Assim, conhecendo os dois fatores considerados relevantes no contexto do estudo, a característica e o treinamento empreendedor, torna-se possível estabelecer a segunda hipótese com relação à intenção empreendedora.

$\mathrm{H} 2$ : $\mathrm{O}$ treinamento empreendedor possui algum efeito positivo e significativo na intenção de empreender.

O modelo de análise da pesquisa foi constituído pelas variáveis independentes característica empreendedora e treinamento empreendedor, buscando testar o seu efeito na variável dependente intenção empreendedora, conforme modelo adaptado de Küttim et al. (2014) e Adekiya e Ibrahim (2016).

Figura 1 - Modelo de análise da pesquisa

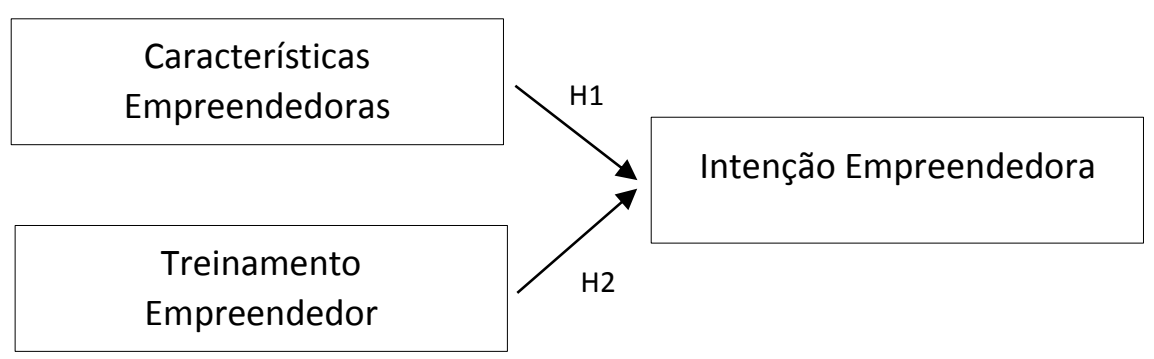

Fonte: Adaptado de Küttim et al. (2014) e Adekiya e Ibrahim (2016).

\section{METODOLOGIA}

O método de pesquisa, quanto ao tipo de investigação, tem delineamento quantitativo, de caráter descritivo. A área de pesquisa corresponde ao campus Francisco Beltrão da Universidade Tecnológica Federal do Paraná. 
Intenção empreendedora entre estudantes universitários:

influência das características e treinamento empreendedor

A pesquisa quantitativa teve como objetivo analisar a influência da característica e do treinamento empreendedor na intenção empreendedora dos alunos regularmente matriculados, sendo a população composta por 778 alunos no segundo semestre de 2018, com a técnica de amostragem probabilística, admitindo erro amostral de $5 \%$, obtendo a amostra de 403 respondentes. Assim, participaram da pesquisa 97 discentes do curso de Licenciatura em Informática, 55 de Engenharia de Alimentos, 106 de Engenharia Ambiental e 145 de Engenharia Química.

O instrumento de pesquisa corresponde ao modelo adaptado de Küttim et al. (2014) e Adekiya e Ibrahim (2016), com aplicação de pré-teste aos estagiários do Proem - Programa de Empreendedorismo e Inovação - matriculados na universidade, que testaram o questionário quanto à formulação e interpretação.

Os dados foram coletados por meio de aplicação do questionário em formato online, aplicado diretamente aos alunos em sala de aula, no formato transversal, realizada em um determinado período de tempo, conforme Hair Jr et al. (2005).

A escala utilizada é do tipo Likert, composta por um conjunto de itens, em relação a cada um dos quais se pede ao estudante manifestar seu grau de concordância, desde discordo (nível 1) até concordo totalmente (nível 5). A escala possui 39 itens, sendo 24 relativas à característica empreendedora (carac1 a carac24); seis dizem respeito ao treinamento empreendedor (trein1 a trein6); e, nove analisam a intenção empreendedora (int1 a int9).

Para validade do instrumento de mensuração, utilizou-se o alfa de Cronbach, obtendo-se a seguinte confiabilidade: 0,$872 ; 0,893 ; 0,938$, para as variáveis dependentes característica e intenção empreendedora; e para a variável independente intenção empreendedora, respectivamente. De acordo com Hair Jr et al. (2005), trata-se de índices muito bom e excelente.

Com os resultados da confiabilidade do instrumento, prosseguiu-se o estudo por meio da Análise Descritiva, Assimetria e Curtose; Análise Kaiser-Meyer-Olkin (KMO) e Bartlett's test (esferidade de Bartlett); Análise Fatorial; e, Análise de Regressão Multivariada, para confirmação dos dados e do modelo.

\section{RESULTADOS E DISCUSSÕES}

\subsection{Estatística descritiva, assimetria, curtose e análise fatorial}

Quanto à estatística descritiva, na tabela 1, é possível observar os 39 itens que compõem o modelo, assimetria e curtose. As médias totais variam entre 2,74 e 4,13 e os desvios padrão entre 0 e 1 . Na variável independente "característica empreendedora", as maiores médias, acima de 3,90, encontram-se nas questões "Prefiro uma atividade repleta de novidades a uma atividade rotineira"; "Nesta sociedade, tornar-se empresário é mais apreciado do que ser empregado"; "Não tenho medo de errar e aprendo com os erros"; e, "Começar um negócio é mais gratificante do que trabalhar para outra pessoa"; com 4,07; 3,$97 ; 3,95 ; 3,93$, respectivamente. Com relação a variável independente "treinamento empreendedor", as questões "A introdução de cursos de desenvolvimento de empreendedorismo na Universidade é necessária"; "Capacitação e treinamento sobre legislação e regulamentação relacionadas ao empreendedorismo são necessários na Universidade"; e, "Aprenderia muito com cursos sobre desenvolvimento de empreendedorismo, se eles fossem ofertados", apresentaram as maiores médias com 4,13; 
4,09; 4,05, respectivamente. As questões "Se eu tivesse a oportunidade e os recursos, gostaria de iniciar uma empresa" e "Estou determinado a criar uma empresa no futuro", da variável dependente "intenção empreendedora" apresentaram as maiores médias com 3,76 e 3,59, respectivamente.

As médias gerais 3,94 da variável "treinamento" e 3,5 da variável "intenção" são consonantes com os estudos de Adekiya e Ibrahim (2016), que apresentaram 3,7 para o treinamento e 3,76 para a intenção de empreender. Segundo os autores, esta pontuação indica uma alta percepção quanto a demanda sobre treinamento empreendedor, bem como um moderado envolvimento na intenção em desenvolver práticas empreendedoras em um futuro próximo. Ferreira, Alcântara e Freitas (2013) obtiveram o patamar de 3,89 na análise da intenção de empreender dos alunos. Adicionalmente, a pontuação 3,5 da característica empreendedora, demonstrou em todas as variáveis, médias consideráveis quanto aos construtos sugeridos.

Estes valores também apontam que existe certa homogeneidade nas respostas em relação as três variáveis analisadas, já que apresentam médias e desvios muito próximos (MENEGHATTI et al., 2015).

Em termos estatísticos, verifica-se que as variáveis em estudo possuem distribuição normal, uma vez que os coeficientes de curtose e assimetria satisfazem os requisitos de uso da estatística paramétrica (ARAÚJO; CARVALHO, 2016). Todos os valores da assimetria e curtose são $0^{*}$, o que supõe normalidade dos dados em grande medida (HAIR JR et al, 2005).

Quadro 2 - Estatística descritiva, assimetria e curtose

\begin{tabular}{|c|c|c|c|c|c|}
\hline Variáveis & Questões & Média & $\begin{array}{l}\text { Desvio } \\
\text { Padrão }\end{array}$ & Assimetria & Curtose \\
\hline \multirow[t]{7}{*}{$\begin{array}{l}\text { Característica } \\
\text { Empreendedora }\end{array}$} & $\begin{array}{ll}\mathrm{Na} \text { minha } & \text { família, existem } \\
\text { pessoas } & \text { empreendedoras. } \\
\text { (Carac1) } & \end{array}$ & 3,2084 & 1,19752 & $-0,408$ & $-0,601$ \\
\hline & $\begin{array}{l}\text { Creio que tenho habilidade } \\
\text { em detectar oportunidades de } \\
\text { pesquisas e/ou negócios. } \\
\text { (Carac2) }\end{array}$ & 3,2854 & 0,93333 & $-0,320$ & $-0,054$ \\
\hline & $\begin{array}{l}\text { Sempre encontro soluções } \\
\text { criativas para problemas de } \\
\text { estudo e/ou profissionais com } \\
\text { os quais me deparo. (Carac3) }\end{array}$ & 3,4988 & 0,90156 & $-0,334$ & 0,057 \\
\hline & $\begin{array}{l}\text { Prefiro uma atividade repleta } \\
\text { de novidades a uma atividade } \\
\text { rotineira. (Carac4) }\end{array}$ & 4,0769 & 0,96534 & $-0,988$ & 0,656 \\
\hline & $\begin{array}{l}\text { Não tenho medo de errar e } \\
\text { aprendo com os erros. } \\
\text { (Carac5) }\end{array}$ & 3,9529 & 0,96468 & $-0,824$ & 0,378 \\
\hline & $\begin{array}{l}\text { Frequentemente } \\
\text { escolhido como líder em } \\
\text { projetos ou atividades } \\
\text { profissionais. (Carac6) }\end{array}$ & 3,3251 & 1,04907 & $-0,200$ & $-0,329$ \\
\hline & $\begin{array}{l}\text { Eu assumiria uma dívida de } \\
\text { longo prazo, acreditando nas } \\
\text { vantagens que uma }\end{array}$ & 3,2184 & 1,14473 & $-0,235$ & $-0,744$ \\
\hline
\end{tabular}


Intenção empreendedora entre estudantes universitários:

influência das características e treinamento empreendedor

\begin{tabular}{|c|c|c|c|c|}
\hline $\begin{array}{l}\text { oportunidade de negócio me } \\
\text { traria. (Carac7) }\end{array}$ & & & & \\
\hline $\begin{array}{l}\text { Eu sou do tipo empreendedor. } \\
\text { (Carac8) }\end{array}$ & 3,2481 & 1,02115 & $-0,442$ & $-0,165$ \\
\hline $\begin{array}{l}\text { Eu sou do tipo empreendedor } \\
\text { com foco socioambiental. } \\
\text { (Carac9) }\end{array}$ & 3,0422 & 1,09984 & $-0,140$ & $-0,575$ \\
\hline $\begin{array}{l}\text { Para mim, a ideia de um ídolo } \\
\text { é um empreendedor de } \\
\text { sucesso. (Carac10) }\end{array}$ & 3,0744 & 1,14362 & $-0,257$ & $-0,590$ \\
\hline $\begin{array}{l}\text { Carreira } \\
\text { empreendedorismo é uma } \\
\text { carreira aceitável na minha } \\
\text { sociedade. (Carac11) }\end{array}$ & 3,8288 & 0,94261 & $-0,709$ & 0,467 \\
\hline $\begin{array}{l}\text { Começar um próprio negócio } \\
\text { é considerado como } \\
\text { apropriado por muitos nesta } \\
\text { sociedade. (Carac12) }\end{array}$ & 3,6948 & 0,96126 & $-0,471$ & $-0,132$ \\
\hline $\begin{array}{l}\text { Nesta instituição, os } \\
\text { empreendedores são vistos } \\
\text { como modelos. (Carac13) }\end{array}$ & 3,4268 & 0,97556 & $-0,310$ & $-0,031$ \\
\hline $\begin{array}{l}\text { Os empresários são } \\
\text { admirados por pessoas nesta } \\
\text { sociedade. (Carac14) }\end{array}$ & 3,6725 & 0,95777 & $-0,533$ & 0,207 \\
\hline $\begin{array}{l}\text { Nesta sociedade, tornar-se } \\
\text { empresário é mais apreciado } \\
\text { do que ser empregado. } \\
\text { (Carac15) }\end{array}$ & 3,9777 & 1,05661 & $-0,807$ & $-0,070$ \\
\hline $\begin{array}{lr}\text { Eu acredito que eu posso } \\
\text { fazer meus pais, amigos e/ou } \\
\text { companheiro(a) } & \text { feliz } \\
\text { escolhendo } & \text { ser } \\
\text { empreendedor após } & \text { a } \\
\text { formatura. (Carac16) } & \end{array}$ & 3,8635 & 1,00681 & $-0,796$ & 0,368 \\
\hline $\begin{array}{l}\text { As pessoas do meu país são } \\
\text { muito } \\
\text { (Carac17) }\end{array}$ & 3,0471 & 0,95431 & $-0,112$ & $-0,181$ \\
\hline $\begin{array}{l}\text { Conheço várias pessoas que } \\
\text { poderiam me auxiliar } \\
\text { profissionalmente, caso eu } \\
\text { virasse um empreendedor. } \\
\text { (Carac18) }\end{array}$ & 3,2903 & 1,06625 & $-0,303$ & $-0,499$ \\
\hline $\begin{array}{l}\text { Os contatos sociais que tenho } \\
\text { são muito importantes para } \\
\text { minha vida profissional. } \\
\text { (Carac19) }\end{array}$ & 3,5831 & 1,16325 & $-0,493$ & $-0,578$ \\
\hline
\end{tabular}


Paula Regina Zarelli, Evellin Medeiros Otto e Silvestre Labiak Junior

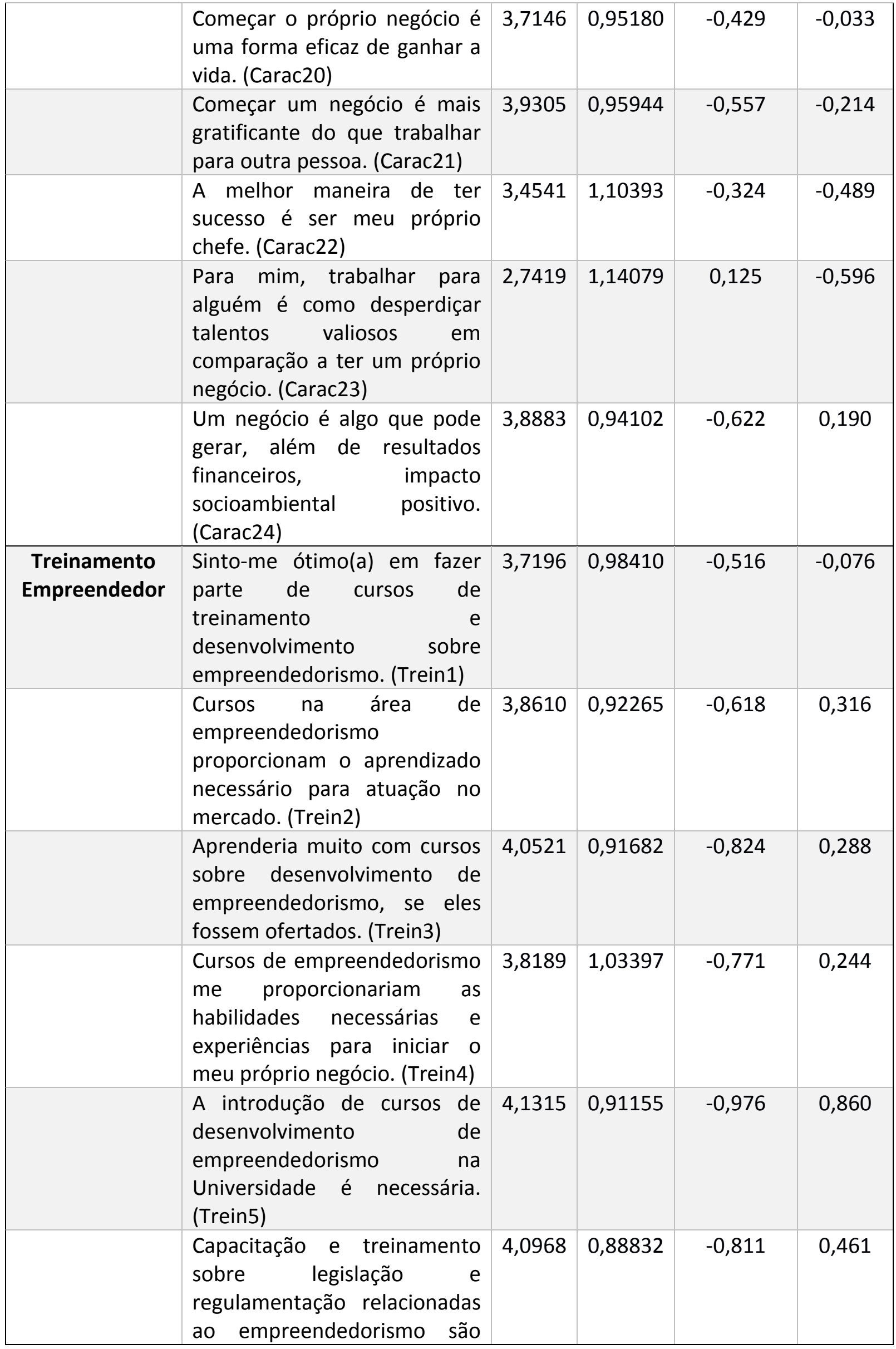


Intenção empreendedora entre estudantes universitários:

influência das características e treinamento empreendedor

\begin{tabular}{|c|l|l|l|l|l|}
\hline $\begin{array}{l}\text { necessários na Universidade. } \\
\text { (Trein6) }\end{array}$ & & & & \\
\hline $\begin{array}{l}\text { Intenção } \\
\text { Empreendedora }\end{array}$ & $\begin{array}{l}\text { Estou pronto para me dedicar } \\
\text { ao máximo para me tornar um } \\
\text { empreendedor. (Int1) }\end{array}$ & 3,4591 & 1,05575 & $-0,351$ & $-0,243$ \\
\hline $\begin{array}{l}\text { É meu plano iniciar o meu } \\
\text { próprio negócio durante a } \\
\text { graduação ou dentro de um } \\
\text { curto prazo após a graduação. } \\
\text { (Int2) }\end{array}$ & 3,3176 & 1,14968 & $-0,219$ & $-0,636$ \\
\hline $\begin{array}{l}\text { Meu objetivo profissional é } \\
\text { tornar-me um empreendedor. } \\
\text { (Int3) }\end{array}$ & 3,4194 & 1,15914 & $-0,318$ & $-0,554$ \\
\hline $\begin{array}{l}\text { Meu objetivo profissional é } \\
\text { tornar-me um empreendedor } \\
\text { com foco socioambiental. } \\
\text { (Int4) }\end{array}$ & 3,1365 & 1,18604 & $-0,086$ & $-0,709$ \\
\hline $\begin{array}{l}\text { Estou determinado a criar } \\
\text { uma empresa no futuro. (Int5) }\end{array}$ & 3,5906 & 1,12352 & $-0,339$ & $-0,641$ \\
\hline $\begin{array}{l}\text { Tenho pensado muito } \\
\text { seriamente em iniciar uma } \\
\text { empresa. (Int6) }\end{array}$ & 3,2903 & 1,22681 & $-0,170$ & $-0,846$ \\
\hline $\begin{array}{l}\text { Se eu tivesse a oportunidade } \\
\text { e os recursos, gostaria de } \\
\text { iniciar uma empresa. (Int7) }\end{array}$ & 3,7692 & 1,11473 & $-0,758$ & 0,013 \\
\hline $\begin{array}{l}\text { Se eu não tivesse recursos, } \\
\text { buscaria formas para } \\
\text { conseguir empreender. (Int8) }\end{array}$ & 3,4119 & 1,10136 & $-0,364$ & $-0,392$ \\
$\begin{array}{l}\text { Entre diversas opções, eu } \\
\text { prefiro a de ser um } \\
\text { empreendedor. (Int9) }\end{array}$ & 3,2804 & 1,14531 & $-0,175$ & $-0,584$ \\
\hline & & & & \\
\hline
\end{tabular}

Fonte: dados da pesquisa.

Na segunda etapa, procedeu-se a análise fatorial, que estuda o problema de analisar a estrutura das inter-relações (correlações) entre um grande número de variáveis [...] definindo um conjunto de dimensões latentes comuns, chamada de fatores. (HAIR JR et al., 2005; APPIO; TONTINI; SILVEIRA, 2013). Como a análise fatorial busca descobrir a validade das questões que compõem o construto, por meio do agrupamento das variáveis, procedeuse a análise pelos métodos mais comuns denominados - Varimax e Kaiser Normalization. Como medida de adequação da amostra optou-se pelos testes de Kaiser-Meyer-Olkin (KMO) e esfericidade de Bartlett.

Para Turra e Baço (2014), a rotação ortogonal pelo método Varimax procura minimizar o número de variáveis fortemente relacionadas com cada fator, permitindo, assim, obter fatores mais facilmente interpretáveis.

Para Hair Jr et al. (2005), os valores entre 0,5 e 0,7 são medíocres, valores entre 0,7 e 0,8 são bons e valores entre 0,8 e 0,9 são muito bons, ou seja, valores maiores que 0,5 
indicam que o método é adequado para o tratamento dos dados do modelo. Após testes KMO e Bartlett, verificam-se as comunalidades, que dizem respeito a uma "quantia total de variância que uma variável original compartilha com todas as outras variáveis incluídas na análise (...) o pesquisador deve ver a comunalidade de cada variável para avaliar se ela atende a níveis de explicação aceitáveis (HAIR JR et al., 2005, p. 91). Nesta análise, valores abaixo de 0,5 são excluídos e todo o teste KMO e Bartlett são refeitos após exclusão.

A "característica empreendedora" apresentou o índice 0,867 com alta significância $(p=0,000)$ no teste de Bartlett. O grau de ajuste dos dados indica que o método é adequado para o tratamento dos dados. As comunalidades abaixo de 0,5 foram excluídas, e a rotação Varimax com normalização de Kaiser, usando método dos componentes principais, resultou em $83 \%$ da variância total explicada, com alta significância $(p=0,000)$. Ou seja, $83 \%$ da variância do modelo é explicada por cada fator.

O "treinamento empreendedor" demonstrou o índice 0,858 com alta significância $(p=0,000)$ no teste de Bartlett. Não houve comunalidades abaixo de 0,5 , e a rotação Varimax com normalização de Kaiser, usando método dos componentes principais, resultou em $85 \%$ da variância total explicada.

A "intenção empreendedora" apresentou o índice 0,939 com alta significância $(p=0,000)$ no teste de Bartlett. Não houve comunalidades abaixo de 0,5 , e a rotação Varimax com normalização de Kaiser, usando método dos componentes principais, resultou em 93\% da variância total explicada. Todos os construtos considerados muito bons para interpretação da variância (HAIR JR et al., 2005). A tabela 2 expõe as cargas fatoriais obtidas dos construtos.

Quadro 3 - Análise Fatorial

\begin{tabular}{|c|c|c|}
\hline Construto & Variável & Carga Fatorial (extração) \\
\hline Característica Empreendedora & Carac2 & 0,725 \\
\hline & Carac3 & 0,562 \\
\hline & Carac8 & 0,702 \\
\hline Carac9 & 0,575 \\
\hline Carac11 & 0,507 \\
\hline Carac13 & 0,725 \\
\hline Treinamento Empreendedor & Carac14 & 0,670 \\
\hline Carac18 & 0,534 \\
\hline Carac19 & 0,573 \\
\hline Carac20 & 0,565 \\
\hline Intenção Empreendedora & Carac21 & 0,618 \\
\hline & Carac22 & 0,669 \\
\hline & Carac23 & 0,530 \\
\hline & Tr03 & 0,588 \\
\hline & Tr04 & 0,737 \\
\hline & Tr02 & 0,685 \\
\hline & Tr06 & 0,673 \\
\hline & Tr05 & 0,653 \\
\hline & Tr01 & 0,652 \\
\hline Int03 & 0,530 \\
\hline Int06 & 0,772 \\
\hline Int05 & 0,748 \\
\hline & & 0,731 \\
\hline
\end{tabular}


Intenção empreendedora entre estudantes universitários:

influência das características e treinamento empreendedor

\begin{tabular}{|l|c|c|}
\hline & Int08 & 0,716 \\
\hline & Int02 & 0,706 \\
\hline Int09 & 0,700 \\
\hline Int07 & 0,628 \\
\hline Int01 & 0,535 \\
\hline
\end{tabular}

Fonte: dados da pesquisa.

Em Turra e Baço (2014) tem-se que, quanto maior uma carga fatorial, mais associada com o fator se encontra a variável.

As maiores cargas fatoriais quanto ao construto "característica empreendedora" referem-se às variáveis "Creio que tenho habilidade em detectar oportunidades de pesquisas e/ou negócios (Carac2: 0,725)"; "Nesta instituição, os empreendedores são vistos como modelos (Carac13: 0,725)"; e, "Eu sou do tipo empreendedor (Carac8: 0,702)".

No que diz respeito ao "treinamento empreendedor", a variável "Aprenderia muito com cursos sobre desenvolvimento de empreendedorismo, se eles fossem ofertados" demonstrou maior carga fatorial (Tr03: 0,737).

O construto "intenção empreendedora" apresentou as variáveis com maiores cargas "Meu objetivo profissional é tornar-me um empreendedor" (Int03: 0,772); "Tenho pensado muito seriamente em iniciar uma empresa" (Int06: 0,748); "Estou determinado a criar uma empresa no futuro" (Int05: 0,731); "Se eu não tivesse recursos, buscaria formas para conseguir empreender" (Int08: 0,716); “É meu plano iniciar o meu próprio negócio durante a graduação ou dentro de um curto prazo após a graduação" (Int02: 0,706); e, "Entre diversas opções, eu prefiro a de ser um empreendedor" (Int09: 0,700).

A análise fatorial exploratória definiu o agrupamento das variáveis com os escores ou cargas fatoriais que formaram os construtos. A matriz de comunalidades forneceu as variáveis válidas e a redefinição dos construtos foi efetuada com base na matriz de componente rotativa, em consonância com os resultados da matriz da variância total explicada.

\subsection{Influência da característica e treinamento empreendedor na intenção de empreender}

A regressão linear múltipla permitiu analisar a intenção empreendedora dos alunos e os fatores que a influenciam. Após agrupamento das variáveis na análise fatorial, obteve-se o modelo resultante com o método stepwise, que elimina problemas de colinearidade/multicolinearidade quando elimina variáveis com combinação linear próxima (HAIR JR et al., 2005). De acordo com os autores, o objetivo da análise é usar as variáveis independentes cujos valores são conhecidos para prever os valores da variável dependente selecionada pelo pesquisador. Cada variável independente é ponderada pelo procedimento da análise de regressão para garantir máxima previsão a partir do conjunto de variáveis independentes. O conjunto de variáveis independentes ponderadas forma a variável estatística da regressão, uma combinação linear das variáveis independentes que melhor prevê a variável dependente. Em termos percentuais, significa qual o percentual que explica a variável, ou que valida o modelo proposto.

\begin{tabular}{|c|c|c|c|c|c|c|}
\hline Modelo & $\begin{array}{c}\text { Variável } \\
\text { Dependente }\end{array}$ & $\begin{array}{c}\text { Variável } \\
\text { Independente }\end{array}$ & $\mathbf{R}$ & $\mathbf{R}^{2}$ & $\begin{array}{c}\mathbf{R}^{2} \\
\text { Ajustado }\end{array}$ & Sig.* \\
\hline 1 & Característica & Intenção & 0,688 & 0,473 & 0,468 & 0,000 \\
\hline
\end{tabular}


Paula Regina Zarelli, Evellin Medeiros Otto e Silvestre Labiak Junior

\begin{tabular}{|c|c|c|c|c|c|c|}
\hline & Empreendedora & Empreendedora & & & \\
\hline $\mathbf{2}$ & $\begin{array}{c}\text { Treinamento } \\
\text { Empreendedor }\end{array}$ & $\begin{array}{c}\text { Intenção } \\
\text { Empreendedora }\end{array}$ & 0,506 & 0,256 & 0,254 & 0,000 \\
\hline
\end{tabular}

Fonte: dados da pesquisa.

*Significância $p<0,05$

O modelo 1 considerou o construto "característica empreendedora" como preditor da variável "intenção empreendedora", com $\mathrm{R}^{2}=0,473(p=0,000)$. Este resultado indica que a intenção empreendedora é $47,3 \%$ significativa e positivamente explicada pela característica empreendedora, e variáveis do modelo, confirmando-se a hipótese H1.

Oliveira et al. (2016) obtiveram 40,8\% da variância explicada na intenção empreendedora pela auto eficácia, atitude e norma subjetiva empreendedora, corroborando os resultados do estudo. Araújo e Carvalho (2016) observaram o comportamento inovador como perfil empreendedor com 0,492 da variância explicada pelas características persistência; assumir riscos; liderança; inovador; detecta oportunidades; planejador; auto eficaz; sociável, apresentando resultados consonantes com o presente estudo.

Adicionalmente, Meneghatti et al. (2015) mencionam que aspectos culturais, valores individuais, e capacidade de resolução de problemas, que são resultado de um processo de aprendizagem de longo prazo, são alguns elementos que podem auxiliar a caracterizar o indivíduo empreendedor.

O modelo 2 considerou o construto "treinamento empreendedor" como preditor da variável "intenção empreendedora com $\mathrm{R}^{2}=0,256(p=0,000)$. Este resultado indica que a intenção empreendedora é $25,6 \%$ significativa e positivamente explicada pela característica empreendedora, e variáveis do modelo, corroborando a hipótese $\mathrm{H} 2$.

Em Küttim et al. (2014), verificou-se que a participação em ofertas de educação para o empreendedorismo tem um provável impacto positivo sobre intenções empreendedoras, com $30 \%$ da variação nas intenções.

Quanto à satisfação com as ofertas de formação para o empreendedorismo, estudos têm mostrado que em países voltados para a eficiência existem mais empreendedores em potencial do que em países impulsionados pela inovação, o que também poderia ser responsável por maiores participação e satisfação com as ofertas de capacitação para o empreendedorismo (KÜTTIM et al., 2014).

Adekiya e Ibrahim (2016) também apontam um provável efeito positivo $(>0,3)$ nas intenções empresariais em termos de participação na educação para o empreendedorismo. A conclusão dos autores foi de que a participação na educação para o empreendedorismo provavelmente fortalecerá o empreendedorismo. A figura 2 demonstra o modelo confirmatório da investigação.

Figura 2 - Modelo confirmatório da pesquisa

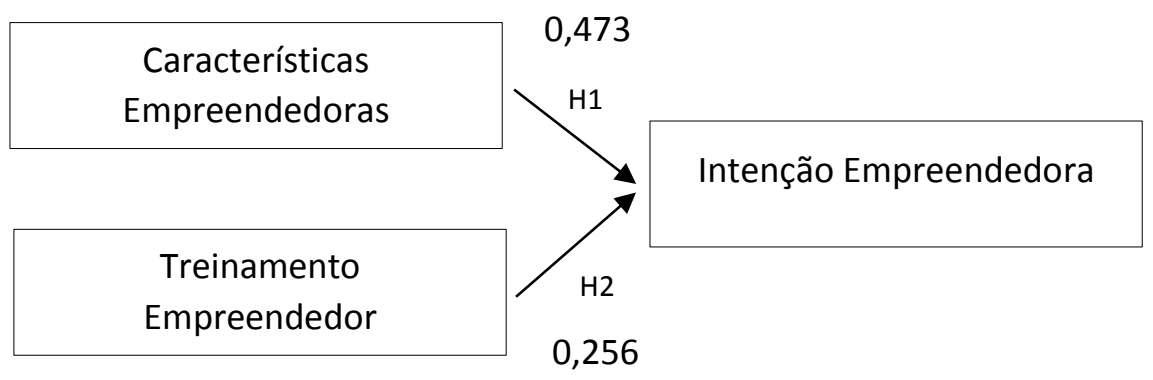


Intenção empreendedora entre estudantes universitários:

influência das características e treinamento empreendedor

Fonte: dados da pesquisa.

Dessa forma, os dois construtos, característica e treinamento empreendedor explicam a variância da intenção de empreender. O modelo proposto neste estudo constitui um valor semelhante encontrado em investigações prévias expostas por Oliveira et al. (2016), desde Autio et al. (2001), 20\% a Liñán et al. (2013), 65\%, o que aprofunda a análise empírica das variáveis consideradas.

De acordo com Digen (2008), jovens universitários têm a necessária capacidade técnica, a maturidade profissional e a experiência para visualizarem e desenvolverem as oportunidades de negócio. É nesse ponto, que a maioria necessita do apoio e da orientação de um curso de empreendedorismo para ajudá-los no desenvolvimento de oportunidades de negócio voltadas para o desenvolvimento sustentável e para a redução da pobreza, além dos aspectos inovativos.

\section{CONCLUSÕES E ESTUDOS FUTUROS}

Pode-se perceber em estudos anteriores que a inserção de atividades relacionadas à capacitação e ao empreendedorismo afetam a intenção empreendedora de alunos de graduação.

Assim, este estudo objetivou analisar a influência das características e do treinamento empreendedor na intenção empreendedora de estudantes universitários da Universidade Tecnológica Federal do Paraná, campus Francisco Beltrão.

Implicações acadêmicas podem ser observadas nos resultados da análise de regressão multivariada, que indicam que as variáveis no modelo influenciam as intenções empreendedoras relativamente uniformemente. Da mesma forma que as conclusões de outros estudos, é provável que a característica e o treinamento empreendedor estejam positivamente conectados à intenção empreendedora. Em termos de mensuração, a utilização da análise fatorial reduziu as variáveis às cargas fatoriais e confirmou o modelo de influência das características e treinamento empreendedor na intenção de empreender entre estudantes universitários.

No entanto, o estudo possui certas limitações, de forma que os resultados devem ser interpretados com ponderação. Por tratar-se um estudo transversal, e apesar de estudos anteriores explicarem a variância do construto "intenção de empreender", é importante realizar estudos longitudinais para testar essa influência no campo do empreendedorismo. As características empreendedoras seguiram os modelos de Küttim et al. (2014) e Adekiya e Ibrahim (2016), extraídas do cenário internacional, sendo necessária a inclusão de características reconhecidas nacionalmente em futuros estudos. O construto "treinamento empreendedor" foi eleito em detrimento da "educação empreendedora", por testar a relação em uma instituição que oferece os treinamentos em forma de programa, como atividade de caráter extensionista e de inovação, complementar ao projeto pedagógico de seus cursos de graduação, o que não reduz a importância em se considerar em estudos futuros a educação empreendedora sob um viés mais amplo de análise, a partir do foco didático-pedagógico. Adicionalmente, o resultado $(<0,3)$ é indicativo de um baixo, apesar de positivo e significativo, impacto do treinamento empreendedor como preditor no construto intenção em empreender, o que sugere uma avaliação da abrangência e da metodologia empregada no programa aplicado pela instituição objeto do estudo. 
Küttim et al. (2014) sugerem a inclusão de variáveis como a inovação aberta na educação para o empreendedorismo, incluindo várias partes interessadas nas atividades de ensino e treinamento e vendo isso como um processo de troca de conhecimento.

Complementarmente, é preciso levar em conta outras variáveis como fatores externos envolvidos, ambiente geral e as relações, por exemplo, com a família, as redes e o papel dos modelos provenientes do meio, têm muita importância no desenvolvimento do empreendedorismo (JULIEN, 2010).

Em Lima et al. (2014), encontram-se cinco grandes desafios da educação empreendedora em contexto universitário no Brasil: aumentar a oferta de cursos, disciplinas e atividades ligadas ao empreendedorismo; treinar mais professores; oferecer mais proximidade e contato com os empreendedores e sua realidade; adotar uma abordagem prática; ampliar a diversidade na oferta de disciplinas e atividades ligadas ao empreendedorismo, indo além da tradicional ênfase no plano de negócios, como principais implicações gerenciais ao estudo.

Desta forma, os resultados do presente estudo são significativos dentro do contexto das pesquisas desenvolvidas no Brasil nos temas empreendedorismo, educação empreendedora e a universidade, somando-se aos achados em pesquisas anteriores. Também novos estudos devem ser desenvolvidos no sentido de investigar as relações das diferentes características em períodos iniciais dos cursos e compará-los com os períodos finais, após aplicação dos treinamentos, uma vez que a absorção dos conhecimentos pode variar, influenciando assim a intenção em empreender dos alunos.

Adicionalmente, tempos atuais como os vivenciados com a pandemia do Covid 19 reforçaram a necessidade da inclusão da visão empreendedora tanto no ensino empreendedor, como na universidade observada de forma holística. A revisão de paradigmas fez-se necessária com a transformação digital "forçada", os desafios das variadas realidades dos alunos quanto ao acesso e aproveitamento das novas modalidades de ensino ofertadas, e outras demandas de cunho econômico e sociais revelaram a oportunidade de adaptação aos novos contextos vigentes, possíveis somente a partir do desenvolvimento de um perfil empreendedor de todos os atores envolvidos.

Por fim, promover a intenção empreendedora não é somente desejável, mas possível, pois a investigação tem dado evidências nesse sentido (OLIVEIRA et al., 2016). Nesta linha, a questão é "o que", "como" e "onde" se capacitar para o empreendedorismo, para tornar os programas de formação empreendedora efetivos tanto em termos características exigidas nos contextos de inovação, por meio dos habitats de inovação e políticas de fomento, como em termos de colocação e crescimento profissionais dos egressos de diversas áreas do conhecimento. A adequação de novas agendas de pesquisa que possam refletir as mudanças globais vem de encontro aos temas abordados por este estudo, no que tange a característica empreendedora para alavancar tais mudanças, sobre a intenção empreendedora para buscar enfrentar os impactos advindos de uma possível crise socioeconômica e a universidade empreendedora como o lócus de suporte aos atores nas diversas discussões, proposições e formações necessárias.

\section{REFERÊNCIAS}

ADEKIYA, A. A.; IBRAHIM, F. Entrepreneurship intention among students. The antecedent role of culture and entrepreneurship training and development. The International Journal of Management Education, v. 14, n. 2, p. 116-132, 2016. 
Intenção empreendedora entre estudantes universitários:

influência das características e treinamento empreendedor

APPIO, J.; TONTINI, G.; SILVEIRA, A. Antecedentes da Lealdade e suas Relações em Instituição de Ensino Superior. Anais do IV Encontro de Ensino e Pesquisa em Administração e Contabilidade, 2013.

AUTIO, E.; KEELEY, R. H.; KLOFSTEIN, M.; PARKER, G. G. C.; HAY, M. Entrepreneurial intent among students in Scandinavia and in the USA. Enterprise and Innovation Management Studies, v. 2, n. 2, p. 145-160, 2001.

ARAÚJO, B. A. G. G. de; CARVALHO, L. C. de. Análise do comportamento inovador e perfil empreendedor dos alunos do ensino superior. Anais do V SINGEP, São Paulo/Brasil, 2016.

COLLINS, O. F.; MOORE, D. G.; UNWALLA, D. The enterprising man and the business executive. MSU Business Topics, v. 12, n. 1, p. 19-34, 1964.

DAL-SOTO, F.; SOUZA, Y. S. de; BENNER, M. A Orientação Empreendedora na Transformação de Universidades. BBR. Brazilian Business Review, v. 18, p. 255-277, 2021.

DEGEN, R. J. Empreendedorismo: uma filosofia para o desenvolvimento sustentável e a redução da pobreza. Revista de ciências da administração, v. 10, n. 21, p. 11-30, 2008.

DORNELAS, J. C. A. Empreendedorismo corporativo: conceitos e aplicações. Revista de negócios, v. 9, n. 2, 2004.

ECKERT, A.; OLEA, P. M.; DORION, E. C. E.; MECCA, M. S.; ECKERT, M. G. O perfil empreendedor na graduação: um estudo comparativo entre ingressantes e concluintes. Revista Pensamento Contemporâneo em Administração, v. 7, n. 2, p. 61-76, 2013.

FERREIRA, A. C.; CASTRO ALCÂNTARA, V. de; FREITAS, F. M. Adaptação, validação e discussões da aplicação de uma escala de medida do potencial empreendedor em universitários. Revista Pensamento Contemporâneo em Administração, v. 7, n. 3, p. 115138, 2013.

FILION, L. J. Empreendedorismo e gerenciamento: processos distintos, porém complementares. Revista de Administração de Empresas, v. 40, n. 3, p. 8-17, 2000.

FONSECA OLIVEIRA, B. M. da; VIEIRA, D. A.; LAGUÍA, A.; LEÓN, J. A. M.; SOARES, V. J. S. Intenção empreendedora em estudantes universitários: adaptação e validação de uma escala (QIE). Avaliação Psicológica, v. 15, n. 2, p. 187-196, 2016.

FRANCO, J. O. B.; GOUVÊA, J. B. A Cronologia dos Estudos sobre o Empreendedorismo. Revista de Empreendedorismo e Gestão de Pequenas Empresas, v. 5, n. 3, p. 144-166, 2016.

GARCIA, A. S.; RESENDE RIBEIRO, O. C. de; ANDRADE, D. M.; SILVA, J. P. N. Produção científica sobre empreendedorismo social e construção de uma agenda para pesquisas 
futuras: um Estudo Bibliométrico na base Web Of Science (1994-2018) Administração Pública e Gestão Social, v. 13, n. 1, 2021.

GEM. Global entrepreneurship monitor empreendedorismo no Brasil: 2017. Coordenação de Simara Maria de Souza Silveira Greco. Curitiba: IBQP, 2017.

GIBB, A. In pursuit of a new 'enterprise' and 'entrepreneurship'paradigm for learning: creative destruction, new values, new ways of doing things and new combinations of knowledge. International journal of management reviews, v. 4, n. 3, p. 233-269, 2002.

HAIR, J. F.; BLACK, W. C.; BABN, B. J.; ANDERSON, R. E.; TATHAM, R. L. Análise multivariada de dados. Bookman Editora, 2005.

JULIEN, P. A. Empreendedorismo regional e economia do conhecimento. Editora Saraiva, 2017.

JÚNIOR, E. I.; GIMENEZ, F. A. P. Potencial empreendedor: um instrumento para mensuração. Revista de Negócios, v. 9, n. 2, 2004.

KRUEGER JR, N. F.; REILLY, M. D.; CARSRUD, A. L. Competing models of entrepreneurial intentions. Journal of business venturing, v. 15, n. 5-6, p. 411-432, 2000.

KÜTTIM, M.; KALLASTE, M.; VENESAAR, U.; KIIS, A. Entrepreneurship education at university level and students' entrepreneurial intentions. Procedia-Social and Behavioral Sciences, v. 110, p. 658-668, 2014.

LANDSTRÖN, H.; LOHRKE, F. Historical foundations of entrepreneurship research. Great Britain: Edward Elgar Publishing, 2010.

LIMA, E.; HASHIMOTO, M.; MELHADO, J.; ROCHA, R. Caminhos para uma melhor educação superior em empreendedorismo no Brasil. ENCONTRO NACIONAL DE PESQUISA EM ADMINISTRAÇÃO-ENANPAD, v. 38, 2014.

LIÑÁN, F.; CHEN, Y. Development and cross-cultural application of a specific instrument to measure entrepreneurial intentions. Entrepreneurship theory and practice, v. 33, n. 3, p. 593-617, 2009.

LIÑÁN, F.; CHEN, Y. Testing the entrepreneurial intention model on a two-country sample. Working Papers at the Department of Business, n. 607, p. 1-37, 2006.

LIÑÁN, F.; NABI, G.; KRUEGER, N. British and Spanish entrepreneurial intentions: A comparative study. Revista de economía Mundial, n. 33, p. 73-103, 2013.

LIÑÁN, F.; RODRÍGUEZ-COHARD, J. C.; RUEDA-CANTUCHE, J. M. Factors affecting entrepreneurial intention levels: a role for education. International entrepreneurship and management Journal, v. 7, n. 2, p. 195-218, 2011. 
Intenção empreendedora entre estudantes universitários:

influência das características e treinamento empreendedor

MCCLELLAND, D. C. N. achievement and entrepreneurship: A longitudinal study. Journal of personality and Social Psychology, v. 1, n. 4, p. 389, 1965.

MENEGHATTI, M. R. RIBEIRO, I.; CANCELIER, G. R.; SILVA, J. M. da; SANTOS, P. S. dos. Perfil empreendedor: uma análise a partir de alunos do curso de administração. Revista Eletrônica Científica do CRA-PR-RECC, v. 2, n. 2, p. 48-59, 2016.

MIGUELES, C. Antropologia do consumo: casos brasileiros. FGV Editora, 2007.

MIGUEZ, V. B.; LEZANA, Á. G. R. Empreendedorismo e inovação: a evolução dos fatores que influenciam o empreendedorismo corporativo. Navus: Revista de Gestão e Tecnologia, v. 8, n. 2, p. 112-132, 2018.

LEÓN, J. A. M.; GORGIEVSKI, M.; LAGUNA, M. STEPHAN, U.; ZARAFSHANI, K. A cross-cultural approach to understanding entrepreneurial intention. Journal of career development, v. 39, n. 2, p. 162-185, 2012.

LEÓN, J. A. M.; JIMÉNEZ, A. G.; LAGUNA, M.; ROZNOWSKI, B. Validación de un cuestionario para medir la intención emprendedora: una aplicación en España y en Polonia. In: Método, teoría e investigación en psicología social. Pearson Educación, 2008. p. 101-122.

LEÓN, J. A. M.; PALACÍ DESCALS, F. J.; MORALES DOMÍNGUEZ, J. F. El perfil psicosocial del emprendedor universitario. Revista de Psicología del Trabajo y de las Organizaciones, v. 22, n. 1, 2006.

OLIVEIRA, E. M. Empreendedorismo social no Brasil: atual configuração, perspectivas e desafios-notas introdutórias. Revista da FAE, v. 7, n. 2, 2004.

OLIVEIRA, J. M. de. Modelo para a integração dos mecanismos de fomento ao empreendedorismo no âmbito das universidades: o caso da Universidade Federal do Rio Grande do Sul. 2006. 203f. Tese (Doutorado) - Programa de Pós-Graduação em Engenharia de Produção, Universidade Federal de Santa Catarina (UFSC), Florianópolis, 2006.

PIRES, V.; PICCHIAI, D.; AYRES, M. Um estudo de caso sobre a formação empreendedora em cursos técnicos através da percepção de discentes egressos. RACEF - Revista de

Administração, Contabilidade e Economia da Fundace. v. 12, n. 1, p. 92-106, 2021.

PHILPOTT, K.; DOOLEY, L.; O'REILLY, C.; LUPTON, G. The entrepreneurial university:

Examining the underlying academic tensions. Technovation, v. 31, n. 4, p. 161-170, 2011.

RAMOS, M. da C. P. Solidariedade, inovação social e empreendedorismo no desenvolvimento local. The Overarching Issues of the European Space. Ed. Faculdade Letras Universidade do Porto, p. 313-342, 2013.

RIVERA, R. G. SANTOS, D.; MARTÍN-FERNÁNDEZ, M.; REQUERO, B.; CANCELA, A. Predicting attitudes and behavioural intentions towards social entrepreneurship: the role of servant leadership in young people/Predicción de las actitudes y las intenciones conductuales hacia 
el emprendimiento social: el papel del liderazgo de servicio en los jóvenes. Revista de Psicología Social, v. 33, n. 3, p. 650-681, 2018.

SAMPIERI, R. H.; COLLADO, C. F.; LUCIO, P. B. Metodología de la investigación. McGraw-Hill Interamericana de España S.L., 1998.

SILVA, P. C. R. da. Práticas sustentáveis de empreendedorismo social. 2009. Disponível em: http://agildoc.com/wp-content/uploads/2017/07/PR\%C3\%81TICAS-SUSTENT\%C3\%81VEISDE-EMPREENDEDORISMO-SOCIAL.pdf.

SCHAEFER, R.; MINELLO, I. F. Educação empreendedora: premissas, objetivos e Metodologias. Revista Pensamento Contemporâneo em Administração, v. 10, n. 3, p. 60-81, 2016.

SOUSA, L. F.; SILVA, R. P.; AFONSO, A. P.; ANJOS COELHO RODRIGUES DIXE, M. dos. Tendência empreendedora dos estudantes do ensino superior. International Journal of Developmental and Educational Psychology: INFAD. Revista de Psicología, v. 1, n. 1, p. 629638, 2011.

SOUZA, E. C. L. de; SOUZA, C. C. L. de; ARAUJO GÓES ASSIS, S. de; ZERBINI, T. Métodos e técnicas de ensino e recursos didáticos para o ensino do empreendedorismo em IES brasileiras. Anais do Encontro Nacional da Associação Nacional de Pós-Graduação e Pesquisa em Administração, 2004.

TURRA, S.; BEZERRA, F. M. Identificação do Nível de Desenvolvimento Regional das Microrregiões Paranaense por meio da Análise Fatorial. Revista de Economia, v. 40, n. 1, 2014.

VALE, G. V.; WILKINSON, J.; AMÁNCIO, R. Empreendedorismo, inovação e redes: uma nova abordagem. RAE-eletrônica, v. 7, n. 1, 2008.

VERGA, E.; SILVA, L. F. S. da. Empreendedorismo: evolução histórica, definições e abordagens. Revista de Empreendedorismo e Gestão de Pequenas Empresas, v. 3, n. 3, p. 330, 2014.

XAVIER, A. B. Atitude empreendedora de estudantes universitários do Distrito Federal. 2018. 77f. Trabalho de Conclusão de Curso (Bacharelado em Administração) - Universidade de Brasília, Brasília, 2018. 